\title{
Development of chromosome-based T7 RNA polymerase and orthogonal T7 promoter circuit in Escherichia coli W3110 as a cell factory
}

\author{
Wan-Wen Ting (1), Shih-I Tan and I-Son Ng ${ }^{*}$ (1)
}

\begin{abstract}
Background: Orthogonal T7 RNA polymerase (T7RNAP) and T7 promoter is a powerful genetic element to mediate protein expression in different cells. Among all, Escherichia coli possess advantages of fast growth rate, easy for culture and comprehensive elements for genetic engineering. As E. coli W3110 owns the benefits of more heat shock proteins and higher tolerance to toxic chemicals, further execution of T7-based system in W3110 as cell factory is a conceivable strategy.

Results: Three novel W3110 strains, i.e., W3110:IL5, W3110::L5 and W3110::pl, were accomplished by chromosomeequipped T7RNAP. At first, the LacZ and T7RNAP with isopropyl- $\beta$-D-thiogalactopyranoside (IPTG) induction showed higher expression levels in W3110 derivatives than that in BL21(DE3). The plasmids with and without lacl/lacO repression were used to investigate the protein expression of super-fold green fluorescence protein (sfGFP), carbonic anhydrase (CA) for carbon dioxide uptake and lysine decarboxylase (CadA) to produce a toxic chemical cadaverine (DAP). All the proteins showed better expression in W3110::L5 and W3110::pl, respectively. As a result, the highest cadaverine production of $36.9 \mathrm{~g} / \mathrm{L}$, lysine consumption of $43.8 \mathrm{~g} / \mathrm{L}$ and up to $100 \%$ yield were obtained in W3110::pl(-) with plasmid pSU-T7-CadA constitutively.

Conclusion: Effect of IPTG and lacl/lacO regulator has been investigated in three chromosome-based T7RNAP E. coli strains. The newly engineered W3110 strains possessed similar protein expression compared to commercial BL21(DE3). Furthermore, W3110::pl displays higher production of sfGFP, CA and CadA, due to it having the highest sensitivity to IPTG, thus it represents the greatest potential as a cell factory.
\end{abstract}

Keywords: E. coli W3110,T7 RNA polymerase, T7 promoter, Recombinant protein, Cadaverine

\section{Introduction}

It is indispensable to develop the recombinant technology which enables enhanced enzyme expression to endorse high-value chemicals production in recent years. The recombinant technology inspired the scientific studies of enzymes, protein and protein interactions and the in vivo chemical production for industrial applications ( $\mathrm{Li}$ and Cirino 2014; Wu et al. 2015). In addition, pharmaceutical and biotechnology companies applied

*Correspondence: yswu@mail.ncku.edu.tw

Department of Chemical Engineering, National Cheng Kung University, Tainan 70101, Taiwan recombinant technology to produce miscellaneous therapeutic proteins with the advantages of high output of the desired proteins, and reduced cost due to the simplified purification processes. For example, recombinant insulin was the first practical therapeutic protein produced by E. coli, and approved by the Food and Drug Administration (Goeddel et al. 1979). Moreover, approximately 30\% recombinant proteins without glycosylation are produced from E. coli (Huang et al. 2012). More prokaryotic and eukaryotic chassis have been explored to produce recombinant therapeutic proteins with different demands.

$E$. coli has been widely used as a genetic strain due to the high growth rate, ease of culture, well-characterized 
genome, and high availability of versatile genetic tools (Rosano and Ceccarelli 2014). With the development of genetic tools and bioinformatics, more possibilities to express foreign proteins and produce valuable chemicals via manipulating the metabolic pathways in $E$. coli have been shown (Atsumi et al. 2008; Du et al. 2014; Wang et al. 2017; Jo et al. 2019). The cellular engineering in E. coli involved plasmid construction (Datta et al. 2006), pET system for overexpression under orthogonal T7RNAP and promoter (Studier and Moffatt 1986), homologous recombination ( $\mathrm{Yu}$ et al. 2000), and also CRISPR/Cas9 technology for genome editing recently (Chung et al. 2016; Jiang et al. 2013; Ng et al. 2016).

The E. coli $\mathrm{B}$ strain and derivatives lacking Lon and OmpT protease empowers to producing heterologous proteins without protease attack. Alternatively, the K-12 strains such as MG1655 and W3110, are commonly used as they express more heat shock genes, less sensitive to certain stress, and possess higher rates of glucose consumption (Kang et al. 2002). A comparative proteomics study between BL21 and W3110 manifested that W3110 maintained growth and metabolism at lower oxygen levels, thus enabling foreign protein to be gradually expressed (Yoon et al. 2012). Therefore, W3110 strain has also been applied to produce various chemicals, including L-malate (Dong et al. 2017), L-methionine (Huang et al. 2017) and L-homoserine (Li et al. 2016).

In this study, a powerful T7 system was equipped in W3110 strain to establish an alternative cell factory. First, T7RNAPs using different promoters, i.e., $\mathrm{P}_{\text {LacUV5 }}$ promoter with or without additional LacI repressor and $\mathrm{P}_{\text {LacI }}$ promoter, were inserted into the W3110 chromosome by a conditional replication, integration, and modular (CRIM) system (Haldimann and Wanner 2001) to develop three engineered W3110 strains. Then, the effect of lacI/lacO was explored by sfGFP as a proof-ofconcept. Furthermore, the new engineered strains were applied to express carbonic anhydrase (CA) for capture of carbon dioxide (Li et al. 2015), and lysine decarboxylase CadA for production of cadaverine (DAP) as a precursor of bio-nylon materials (Huang et al. 2020). We attempted to explore more opportunity of W3110 strain as a new platform to express heterologous protein and produce chemicals.

\section{Materials and methods}

\section{Bacterial strains and culture conditions}

The bacterial strains used in this study are listed in Table 1. The E. coli DH5 $\alpha$ was used for plasmid construction, and BL21(DE3) was applied for gene expression, while W3110 was engineered to equip with a chromosome-based T7RNAP by HK022 phage attack site. All E. coli strains were cultivated in Luria-Bertani (LB) medium at $37^{\circ} \mathrm{C}$ with constant shaking at $200 \mathrm{rpm}$. Antibiotics were added to the following final concentrations as needed: ampicillin $(100 \mu \mathrm{g} / \mathrm{mL})$, kanamycin $(50 \mu \mathrm{g} /$ $\mathrm{mL})$, and chloramphenicol $(25 \mu \mathrm{g} / \mathrm{mL})$.

\section{Construction of CRIM plasmids with T7RNAP under different promoters}

The pHK plasmid was used for inserting an integrated fragment including the HK022 attP, FRT, and multiple cloning sites (Chen et al. 2011). The first CRIM plasmid, pHK-IL5-Km, was designed to create a strain that imitates BL21(DE3), constructed by polymerase chain reaction (PCR) of the BL21(DE3) genome with primers EcoRI-lacI-F and PstI-T7P-R and digested with EcoRI and PstI, cloned into the pHK-Km backbone. The pHKL5-Km was constructed by PCR from pHK-IL5-Km with primers EcoRI-P $\mathrm{Lacuv}_{5}-\mathrm{F}$ and PstI-T7P-R, while plasmid of pHK-pI-Km was cloned by PCR from pDS3.0-HsdNCT7RNAP with primers EcoRI-PlacI-T7P-F and PstIPlacI-T7P-R to obtain T7RNAP under $\mathrm{P}_{\text {LacI }}$ promoter. The primers used are listed in Additional file 1: Table S1.

\section{Engineered chromosome-based T7RNAP in W3110}

Site-specific recombination was applied to integrate T7RNAP into the W3110 genome. This process requires the CRIM plasmid as mentioned above, which includes an attP phage attachment site complementary to the at $\mathrm{B}$ phage attachment site on the genome, and a helper plasmid that includes integrase (Haldimann and Wanner 2001). The helper plasmid pAH69 was transformed into the host strain at first. To prepare competent cells, a transformant cultivated at $30{ }^{\circ} \mathrm{C}$ until the $\mathrm{OD}_{600}$ reached 0.3 ; the temperature then increased to $39^{\circ} \mathrm{C}$ for $30 \mathrm{~min}$ to induce integrase production. The heat-shock transformation was used to transfer the CRIM plasmid into the host strain, followed by recovery at $37^{\circ} \mathrm{C}$ for $2-3 \mathrm{~h}$. Afterwards, positive colonies were screened on LB agar medium with $1 / 3$ kanamycin (i.e., $17 \mu \mathrm{g} / \mathrm{mL}$ ) at $37{ }^{\circ} \mathrm{C}$ to check the integration of the T7RNAP. To construct marker-free strains, pCP20 plasmid was further transformed to remove the resistance fragment flanked between FRT sites by FLP recombinase. One colony was randomly selected and pre-cultured in LB with antibiotic at $30^{\circ} \mathrm{C}$. The cells were inoculated in LB broth without antibiotic and cultured at $37^{\circ} \mathrm{C}$ for $6-8 \mathrm{~h}$, followed by transferring to $39^{\circ} \mathrm{C}$ for $1 \mathrm{~h}$. The cells were then diluted and spread on an LB plate at $37{ }^{\circ} \mathrm{C}$. After overnight cultivating, the colonies were screened on selective plates.

\section{Construction of expression vectors}

The pET28a(+)-sfGFP plasmid was constructed by amplifying the sfGFP fragment from pSU-PlacIsfGFP with primers NdeI-sfGFP-F and XhoI-sfGFP-R, 
Table 1 List of $E$. coli strains and plasmids used in this study

\begin{tabular}{|c|c|c|}
\hline Strains and plasmids & Description & Source or accession number \\
\hline \multicolumn{3}{|l|}{ Strains } \\
\hline W3110 & $\mathrm{F}-, \lambda^{-}, \mathrm{IN}(\mathrm{rrnD}-\mathrm{rrnE}) 1, r p h-1$ & CGSC \#4474 \\
\hline BL21 & $\mathrm{F}^{-}$ompT gal dcm lon hsdS ${ }_{B}\left(r_{B}^{-} m_{B}^{-}\right)\left[m_{a l B^{+}}\right]_{\mathrm{K}-12}\left(\lambda^{5}\right)$ & NEB \#C2530H \\
\hline BL21(DE3) & 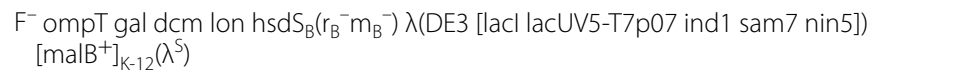 & NEB \#C2527I \\
\hline W3110::IL5 & $\mathrm{F}-, \lambda^{-}$, IN(rrnD-rrnE)1, rph-1 attB (HK022)::Iacl- $\mathrm{P}_{\text {LacUV5- }}$ lacZ'- T7 gene 1 & This study \\
\hline W3110::L5 & $\mathrm{F}-, \lambda^{-}$, IN(rrnD-rrnE) 1, rph-1 attB (HK022):: $\mathrm{P}_{\text {LacUv5 }}$ lacZ'- T7 gene 1 & This study \\
\hline W3110::pl & $\mathrm{F}-, \lambda^{-}$, IN(rrnD-rrnE) 1, rph-1 attB (HK022):: $\mathrm{P}_{\mathrm{Lac}^{-}}{ }^{-}$T7 gene 1 & This study \\
\hline \multicolumn{3}{|c|}{ 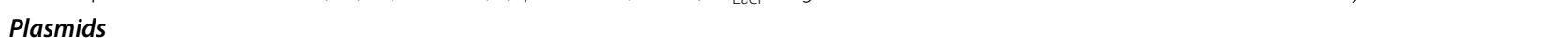 } \\
\hline pAH69 & 4951 bp, Amp ${ }^{R}$, Rep101 ori, repA101 (ts), HK022 integrase, clts857 protein & (Haldimann and Wanner 2001) \\
\hline $\mathrm{pHK-Km}$ & 2539 bp, Kan ${ }^{R}$, R6K ori, FRT- HK022 attp- FRT & (Chen et al. 2011) \\
\hline pDS3.0- HsdNC-T7RNAP & $11,966 \mathrm{bp}, \mathrm{Amp}^{\mathrm{R}}, \mathrm{Gm}^{\mathrm{R}}$, R6K ori, Hsd-N, $\mathrm{P}_{\text {Lacl }}$ promoter, T7 gene1, Hsd-R, sacB & (Yi and $\mathrm{Ng} 2020)$ \\
\hline pHK-IL5-Km & 6933 bp, Kan ${ }^{R}$, R6K ori, FRT- HK022 attp- lacl-P Lacuv5-T7 promoter- lacZ'- T7 gene 1- FRT & This study \\
\hline pHK-L5-Km & 5766 bp, Kan ${ }^{R}$, R6K ori, FRT- HK022 attp- P Lacuv5 ${ }^{-} 77$ promoter- lacZ'- 77 gene 1- FRT & This study \\
\hline pHK-pl-Km & 6586 bp, Kan', R6K ori, FRT- HK022 attp- Hsd-N- $P_{\text {Lacl }}$ promoter- T7 gene1- Hsd-R- FRT & This study \\
\hline pET28a (+)-sfGFP & 6013 bp, Kan², pBR322 ori, lacl, T7 promoter, lacO, sfGFP & This study \\
\hline pSU-T7-sfGFP & 9471 bp, Cm ${ }^{\mathrm{R}}$, pUC ori, T7 promoter, sfGFP & (Tan and Ng 2020) \\
\hline pSU-Placl-sfGFP & 3099 bp, CmR, pUC ori, Placl promoter, sfGFP & (Yi and $\mathrm{Ng} 2020)$ \\
\hline pSU-PlacUV5-sfGFP & 3099 bp, Cm , pUC ori, PlacUV5 promoter, sfGFP & This study \\
\hline pSU- PlacUV5-NRBS-sfGFP & 3099 bp, CmR, pUC ori, PlacUV5 promoter, native RBS, sfGFP & This study \\
\hline pSU-PlacUV5-LacZa'-sfGFP & 3571 bp, $\mathrm{Cm}^{\mathrm{R}}$, pUC ori, PlacUV5 promoter, LacZa, sfGFP & This study \\
\hline pET32a-SyCA & 6595 bp, Amp ${ }^{R}$, pBR322 ori, trxA, lacl, T7 promoter, lacO, SyCA & (Hsu et al. 2019) \\
\hline pET21a (+)-Cas9 & 9471 bp, Amp ${ }^{R}$, pBR322 ori, lacl, T7 promoter, lacO, SpCas9-6His & Lab stock \\
\hline pET20b (+)-Cas9 & 7694 bp, Amp ${ }^{R}$, pBR322 ori, ROP, T7 promoter, Spcas9-6 His & This study \\
\hline pET28a (+)-CadA & 7498 bp, KanR, pBR322 ori, lacl, T7 promoter, lacO, cadA & This study \\
\hline pSU-T7-CadA & 4255 bp, Cm ${ }^{\mathrm{R}}$, pUC ori, T7 promoter, cadA & This study \\
\hline
\end{tabular}

followed by digestion with $\mathrm{NdeI}$ and $\mathrm{XhoI}$ and cloning into pET28a(+)-RFP, which was digested with the same digestion enzymes in advance. The cadA fragment was amplified with HindIII-CadA-F and BglII-CadA-R from E. coli MG1655, digested with HindII and BglII, and inserted into the pSU-T7 backbone, creating the pSUT7-CadA plasmid. The pSU-PlacUV5-sfGFP was constructed by replacing the promoter of pSU-T7-sfGFP and the fragment of $\mathrm{P}_{\text {LacUv5 }}$ was amplified from $\mathrm{pHK}$ L5-Km with primers XbaI-L5-F and BamHI-L5-R. The PCR fragment was digested with $\mathrm{XbaI}$ and $\mathrm{BamHI}$ and cloned into pSU-T7-sfGFP. The pSU-PlacUV5-NRBSsfGFP was constructed by replacing the promoter and RBS of pSU-T7-sfGFP. The inserted fragment was amplified with primers XbaI-L5-F and HindIIIL5-R from pHK-L5-Km, further digested with XbaI and HindIII and cloned into pSU-T7-sfGFP. The pSUPlacUV5-LacZ $\alpha$ 'sfGFP was constructed by inserting the fragment of $\mathrm{P}_{\mathrm{LacUV} 5}-\mathrm{LacZ} \alpha$ ' into the backbone of pSU-T7-sfGFP. The inserted fragment was amplified with $\mathrm{XbaI-L5}-\mathrm{F}$ and HindIII-L5Z-R from pHK-L5-Km. All the plasmids are shown in Table 1.

\section{Culture and induction}

For sfGFP protein and fluorescence analysis, the samples were inoculated with $2 \%(v / v)$ pre-culture broth in $10-\mathrm{mL}$ glass tubes and cultivated in a $37^{\circ} \mathrm{C}$ incubator. IPTG was added to a final concentration of $0.1 \mathrm{mM}$. For the activity measurement of SyCA, $20 \mathrm{~mL}$ LB broth was inoculated with $2 \%(v / v)$ pre-culture broth in a $100-\mathrm{mL}$ flask. As $\mathrm{OD}_{600}$ reached 0.6 to 0.8 . IPTG was added at three different concentrations of $0.005,0.01$ and $0.1 \mathrm{mM}$, and $0.5 \mathrm{mM}$ zinc ions (supplied by $\mathrm{ZnSO}_{4}$ ) were also added. Further keep cultivating at $37{ }^{\circ} \mathrm{C}$ until $12 \mathrm{~h}$. For the protein analysis of CadA, $10 \mathrm{~mL}$ LB broth was inoculated with $2 \%(v / v)$ pre-culture cell in a $100-\mathrm{mL}$ flask, when $\mathrm{OD}_{600}$ reached 0.6 to 0.8 , IPTG was added from $0,10^{-5}$, $10^{-4}, 10^{-2}, 10^{-3}$ to $0.1 \mathrm{mM}$ for pET28a $(+)-\operatorname{CadA}$ and $0.1 \mathrm{mM}$ for pSU-T7-CadA.

\section{Measurement of cell growth and fluorescence intensity}

The cell growth was monitored by absorbance at $600 \mathrm{~nm}\left(\mathrm{OD}_{600}\right)$ and the fluorescence intensity was detected by a SpectraMax M2 microreader (Molecular 
Device, USA) with excitation at $480 \mathrm{~nm}$ and emission at $510 \mathrm{~nm}$. All experiments were performed in triplicates.

\section{Protein expression, quantification and identification analysis}

The recombinant protein expression was analyzed by $10 \%$ sodium dodecyl sulfate polyacrylamide gel electrophoresis (SDS-PAGE). After a 12-h culture, the cells were harvested by centrifugation at $12,000 \times g$ for $3 \mathrm{~min}$. The cell concentration was adjusted to OD 4 , and the cells were suspended in $\mathrm{dH}_{2} \mathrm{O}$. The supernatant and cell debris were separated by centrifugation after the whole cells were degraded by a One Shot instrument (Constant Systems, UK). 1D electrophoretic protein separation was achieved by following a standard SDS-PAGE protocol ( $80 \mathrm{~V}, 30 \mathrm{~min} ; 120 \mathrm{~V}, 70 \mathrm{~min})$. Afterwards, the gel was stained with Coomassie brilliant blue G-250 dye for visualization. The band intensities were subsequently quantified by densitometry using ImageLab $^{\circledR}$ (Bio-rad, USA) (Ng et al. 2014). We selected the target protein and standard markers for relative intensity analysis. The target protein was also sent for LC-QTOF mass spectrometer (Applied Biosystems, Lincoln, CA). Injected samples were first trapped and desalted on an LC-Packings PepMap ${ }^{\text {TM }} \mathrm{C} 18 \mu$-Precolumn ${ }^{\text {TM }}$ Cartridge $(5 \mu \mathrm{m}, 5 \mathrm{~mm} \times 30 \mu \mathrm{m}$ I.D.; Dionex, Sunnyvale, CA). Subsequently, peptides were eluted from the precolumn and separated on an analytical LC-Packings PepMap C18 column ( $3 \mu \mathrm{m}, 15 \mathrm{~cm} \times 75 \mu \mathrm{m}$ I.D.) connected in-line to the mass spectrometer, at a flow rate of $200 \mathrm{~nL} / \mathrm{min}$ using a $40-\mathrm{min}$ gradient of 5 to $60 \%$ acetonitrile in $0.1 \%$ formic acid. Only significant hits from the individual MS/MS spectra were considered by mascot probability analysis.

\section{Determination of CA activity by Wilbur-Anderson unit (WAU)}

The CA expressing cells were collected and washed 3 times by deionized water and finally adjusted to OD 5 for further use. The CA activity was determined by Wilbur-Anderson assay as our previous publication (Hsu et al. 2019). Briefly, $9 \mathrm{~mL}$ ice-cold Tris- $\mathrm{HCl}$ (20 mM, pH 8.3) buffer and $0.2 \mathrm{~mL}$ enzyme were mixed and put in a 20-mL sample bottle at $0{ }^{\circ} \mathrm{C}$ under stirring. Then, $6 \mathrm{~mL}$ ice-cold $\mathrm{CO}_{2}$-saturated solution was added into sample bottle immediately. The time in second that $\mathrm{pH}$ value dropped down from 8.3 to 6.3 was recorded and the CA activity was calculated by a Wilbur-Anderson unit (WAU) per milliliter of sample. The definition for WAU is $\left(\mathrm{T}_{0}-\mathrm{T}\right) / \mathrm{T}$, which $\mathrm{T}_{0}$ and $\mathrm{T}$ is the time from $\mathrm{pH} 8.3$ to 6.3 without and with $\mathrm{CA}$.

\section{In vivo DAP production}

A $2 \%(v / v)$ pre-culture was inoculated in a $100-\mathrm{mL}$ flask and cultivated in a $37{ }^{\circ} \mathrm{C}$ incubator. When the $\mathrm{OD}_{600}$ reached $0.5-0.8,0.1 \mathrm{mM}$ IPTG was added as anducer, with $50 \mathrm{~g} / \mathrm{L}$ lysine and $0.01 \mathrm{mM}$ pyridoxal phosphate (PLP) as the substrate and co-factor, respectively. The growth, lysine conversion, and DAP production were measured during 6 to $24 \mathrm{~h}$.

\section{High-performance liquid chromatography (HPLC) analysis of lysine and DAP}

Lysine and DAP derivatives were obtained by combining $340 \mu \mathrm{L} 50 \mathrm{mM}$ borate buffer (pH 9), $240 \mu \mathrm{L} \mathrm{100 \%}$ methanol, $12 \mu \mathrm{L} 200 \mathrm{mM}$ diethyl ethoxymethylenemalonate (DEEMM) without pretreatment, and $6 \mu \mathrm{L}$ of the sample $(<0.1 \mathrm{M})$. The mixture was heated in a $70{ }^{\circ} \mathrm{C}$ water bath for $2 \mathrm{~h}$ to allow complete degradation of excess DEEMM and derivatization (Kim et al. 2015). After derivatization with DEEMM, HPLC was performed with a binary pump, in-line degasser, auto-sampler, and column thermostat. Chromatographic separation was conducted by reverse-phase chromatography on a C18 column (YMC-C18 column, $4.6 \times 250 \mathrm{~mm}, 5-\mathrm{mm}$ particle size) maintained at $35{ }^{\circ} \mathrm{C}$. Mobile phases $\mathrm{A}$ and $\mathrm{B}$ were composed of $25 \mathrm{mM}$ sodium acetate and $100 \%$ acetonitrile, respectively. A flow rate of $0.8 \mathrm{~mL} / \mathrm{min}$ was used, with the following gradient program: $0-2 \mathrm{~min}, 80 \%-75 \% \mathrm{~A}$; 2-30 $\mathrm{min}, 75 \%-40 \% \mathrm{~A} ; 30-35 \mathrm{~min}, 40 \%-80 \% \mathrm{~A}$. The UV detector operated at a wavelength of $284 \mathrm{~nm}$.

\section{Results}

\section{Engineered $E$. coli W3110 equipped with T7RNAP}

Three different T7RNAP cassettes were constructed and integrated into the chromosome of W3110 by traditional site-specific recombination at the att $\mathrm{B}$ sites of lambdoid coliphage HK022 (Fig. 1a). The first strain, denoted as W3110::IL5 and was similar to BL21(DE3), contained a T7 gene 1 driven by $\mathrm{P}_{\text {LacUv5 }}$ with lac $\mathrm{O}$ and an additional lacI genes located upstream of the promoter. Second strain was W3110::L5, in which additional lacI was not presented at upstream of the $\mathrm{P}_{\text {LacUv5 }}$ promoter. The third strain, W3110::pI, was significantly different from the previous two strains because the $T 7$ gene 1 was driven by $\mathrm{P}_{\text {Lacl }}$, which is widely used in iGEM (https://parts.igem. org/Part:BBa_R0010). The newly created strains were verified by amplifying characteristic fragments of each strain (Fig. 1b) at first, and further confirmed by sequencing (Additional file 1: Fig. S1), and the result showed that all strains were successfully constructed.

The cell growth (Additional file 1: Fig. S2), LacZ and T7RNAP protein expressions (Fig. 2) were compared among three engineered W3110 strains equipped with 


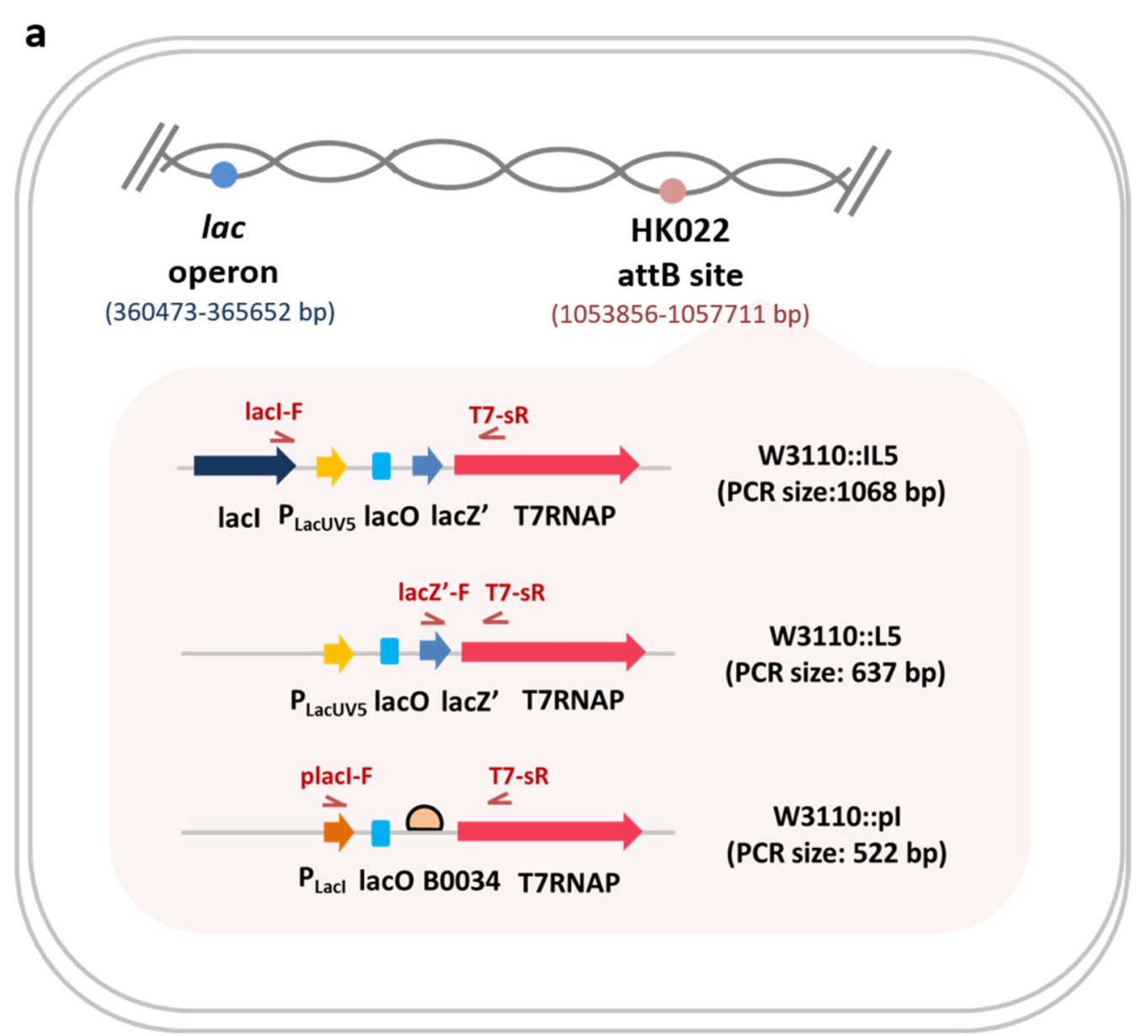

b

M

1

2

3

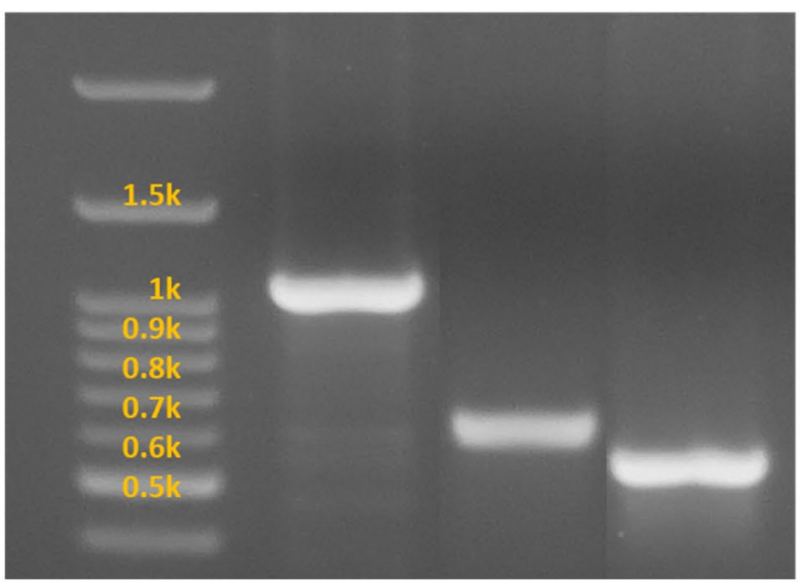

Fig. 1 Schematic diagram of the engineered W3110 strain with chromosome-equipped T7RNAP a genetic design of engineered T7RNAP in E. coli W3110. Integration was achieved by site-specific recombination at the HK022 attB site. Three engineered T7RNAP expression strains were created. The strain W3110:IL5 has a lacl-P Lacuv5-lacZ'-T7RNAP copy from BL21(DE3), and W3110::L5 lacks an additional integrated lacl. W3110::pl, in which T7RNAP is driven by the $P_{\text {Lacl }}$ without additional repressor and lacZ' sequence near the promoter. The characteristic fragments of each strain were labeled by primers and result of confirmation was showed in $\mathbf{b}$ : lane 1: PCR with primer lacl-F and T7-sR of W31 10:IL5, lane 2: PCR with primer lacZ'-F and T7-sR of W3110::L5, lane 3: PCR with primer Placl-F and T7-sR of W3110::pl. The desired fragment of lacl-F and T7-sR is 1068 bp, lacZ'-F and T7-sR is $637 \mathrm{bp}$ and $522 \mathrm{bp}$ for Placl-F and T7-sR. M: 100 bp marker 


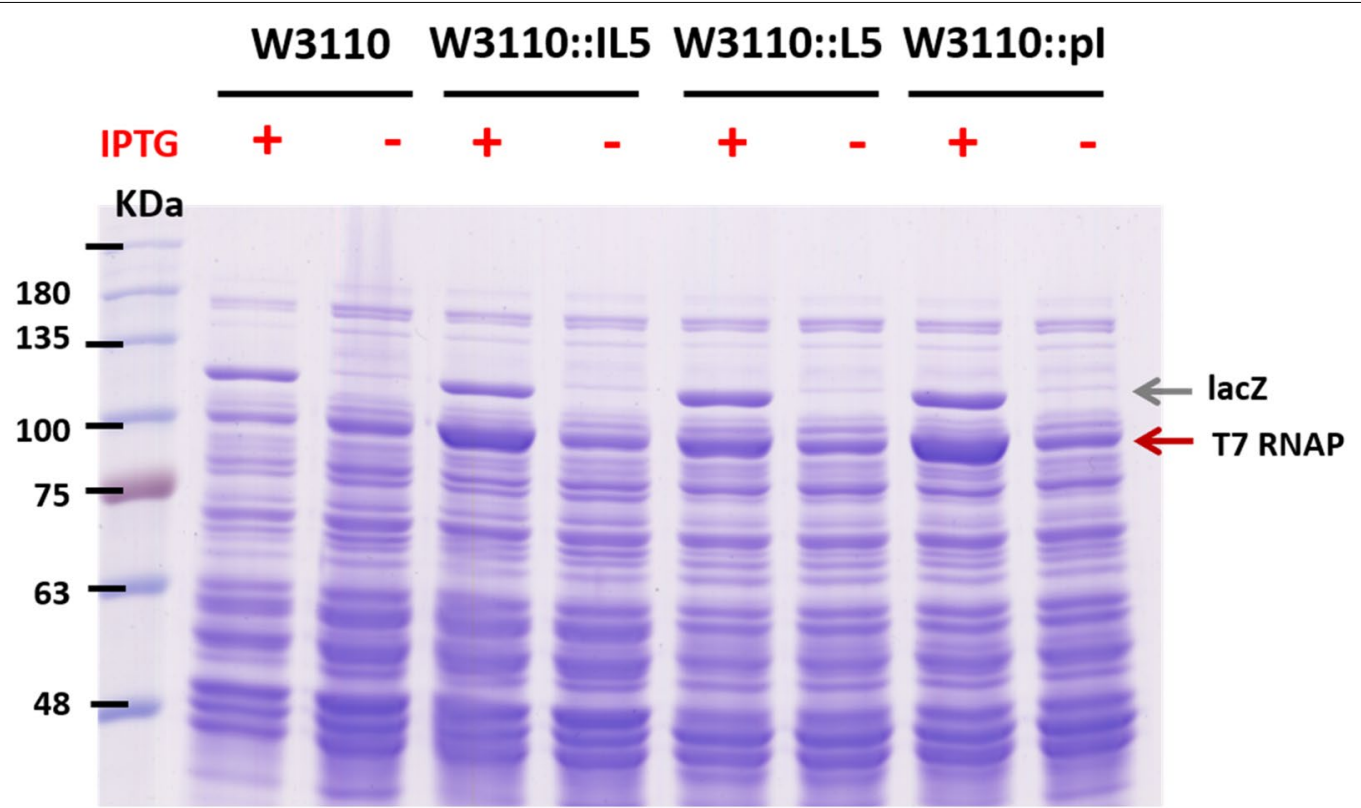

Fig. 2 The protein expression analysis of four E. coli strains with and without induction by $0.1 \mathrm{mM}$ IPTG. The LacZ protein is approximately $116.4 \mathrm{kDa}$, as indicated by the gray arrow. The T7RNAP was approximately $98.8 \mathrm{kDa}$, as indicated by the red arrow

Table 2 MS/MS analysis of T7 RNA polymerase and lacZ gene from engineered E. coli W3110

\begin{tabular}{lllrr}
\hline No. & Protein & Accession no. & Score & $\begin{array}{r}\text { Molecular weight (Mw, } \\
\text { kDa) }\end{array}$ \\
\hline 1 & T7-like RNA polymerase & WP_001092355 & 955 & 98.79 \\
2 & LacZ beta-galactosidase & WP_096183704 & 1036 & 116.42 \\
\hline
\end{tabular}

the T7RNAP. The biomass at the log-phase was the same in each strain expect for W3110::L5 between the condition with or without IPTG induction, while, the biomass was similar at the OD ranging from 2.2 to 2.5 at $12 \mathrm{~h}$. Furthermore, to confirm the protein expression, SDS-PAGE was performed and showed there were two distinct bands as comparing between the condition with and without IPTG. The identities of distinct proteins were analyzed by LC-MS/MS and the results are shown in Table 2, where a band near $100 \mathrm{kDa}$ corresponded to T7RNAP, and the band between 100 and $135 \mathrm{kDa}$ was identified as LacZ. Besides, the quantification was performed based on the ImageLab ${ }^{\circledR}$ and shown in Table 3. The enhancements of LacZ were observed as 2.63-fold for W3110, 3.41-fold for W3110::IL5, 5.21-fold for W3110::L5, and 4.61-fold for W3110::pI (Table 3, LacZ). Furthermore, the T7RNAP expression also reached up to 8.72-fold for W3110::IL5, 6.72-fold for W3110::L5 and 11.92-fold for W3110::pI, implying the $\mathrm{P}_{\text {LacI }}$ promoter and the intact translation level was more effective than that used $\mathrm{P}_{\text {LacUv5 }}$ in W3110.
Table 3 Quantification of relative protein of LacZ and T7RNAP by IPTG induction in BL21(DE3), W3110, W3110::IL5, W3110::L5, W3110::pl

\begin{tabular}{lccccc}
\hline $\begin{array}{l}\text { Relative } \\
\text { protein } \\
\text { amounts }\end{array}$ & BL21(DE3)* & W3110 & W3110::IL5 & W3110::L5 & W3110::pl \\
\hline LacZ & 1.0 & 2.63 & 3.41 & 5.21 & 4.61 \\
T7RNAP & 1.0 & - & 8.72 & 6.72 & 11.92 \\
\hline
\end{tabular}

* LacZ and T7RNAP in BL21(DE3) with IPTG is defined as the reference of $W$ derivatives

Except for the promoter effect, the inserted locus was supposed to be the reason that affect T7RNAP expression in which the locus of engineered W3110 strains was at HK022 attB site (i.e., 1053856-1057711 bp), while that of BL21(DE3) was around the lac operon site (i.e., 360473-365652 bp) (Fig. 1a). With IPTG induction, maximum T7RNAP was observed in W3110::pI while the lowest one was occurred in the W3110::L5 (Table 3, T7RNAP). The feasibility of three strains used 
in protein expression and chemical production was further verified in the following.

\section{Demonstrate $/ a c \mathrm{l} /$ lacO regulation in the new strains by sfGFP}

Two expression vectors, the $\mathrm{pET} 28 \mathrm{a}(+)$ plasmid with the orthogonal lacI/lacO repressor (Fig. 3a), and the pSU-T7 plasmid without repressor were used for evaluation (Fig. 3b). As shown in Fig. 3c, there was no obvious florescence intensity in all strains without IPTG. When IPTG was added, it displayed the level of sfGFP protein with the average fluorescence of 47,000 a.u. in three engineered W3110 strains, but lower expression in BL21(DE3) (i.e., 31,000 a.u.). The sfGFP expression by the pSU-T7-sfGFP plasmid which lacked lacI/lacO, the highest fluorescence intensity of 42,000 a.u. has detected in W3110::pI without IPTG, and the similar florescence intensity at 11,000 a.u. was observed in other strains (Fig. 3d). Consistently, when IPTG was added, the specific fluorescence intensity of W3110::pI was the highest with enhancement of $69 \%, 88 \%$ and $15 \%$ as compared to the BL21(DE3), W3110::IL5 and W3110::L5, respectively
(Fig. 3d). As a result, lacI/lacO was the key component to regulate protein expression in W3110 under IPTG induction and even better than commercial BL21(DE3).

\section{Carbonic anhydrase expression and activity in engineered W3110 strains}

In our previous report, BL21(DE3) overexpressing carbonic anhydrase (CA) showed the arrested cell growth as compared to that without CA expression (Hsu et al. 2019). Therefore, we considered whether W3110 strain would tolerate CA overexpression via pET32a-SyCA. At first, the result of biomass in BL21(DE3) has $30 \%$ reduction at $12 \mathrm{~h}$ which showed the toxicity to the cell (Fig. 4a); however, newly engineered W3110 could tolerate the CA more robustly because the reduced biomass was only $25 \%, 2 \%$ and $18 \%$ for W3110::IL5, W3110::L5 and W3110::pI, respectively (Fig. 4a). Due to lacI/lacO regulation in the plasmid, IPTG induction was required for CA production. The CA activity is shown in Fig. 4b. In BL21(DE3), the CA activity increased from 803 to 1100 WAU as IPTG increased from $0.005 \mathrm{mM}$ to $0.01 \mathrm{mM}$ and kept the similar level with $0.1 \mathrm{mM}$ IPTG. The CA activity

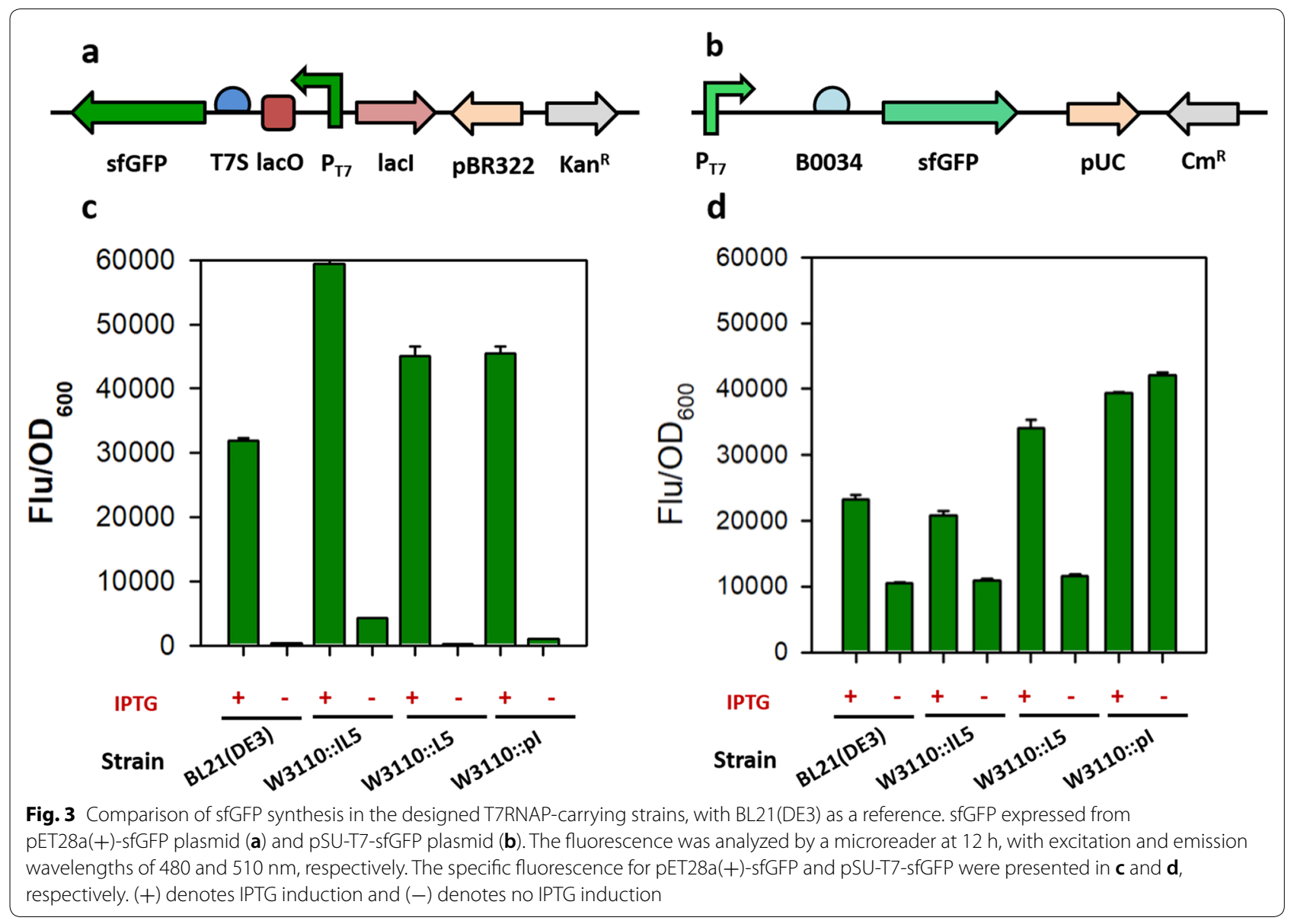





Fig. 4 The cell biomass and enzyme activity of pET32a-SyCA in different engineered E. coli strains. a The relative biomass of different strains harboring pET32a-SyCA with or without 0.1 mM IPTG induction. (+) meant with IPTG and (-) meant without IPTG. Each strain without induction was chosen as standard, respectively. b The activity of crude enzyme of pET32a-SyCA with 0.005, 0.01, 0.1 mM IPTG in different strains determined by Wilbur-Anderson assay

of W3110:IL5 was 1400 WAU with 0.005 mM IPTG and sharply decreased to 400 WAU at that with $0.1 \mathrm{mM}$ IPTG. However, the W3110::L5 and W3110:pI expressed highest CA activity with 1710 WAU at $0.01 \mathrm{mM}$ IPTG and 1795 WAU at 0.005 and $0.01 \mathrm{mM}$ IPTG, respectively. Therefore, the best strain for production of CA is W3110::pI because it maintains the biomass and possesses the highest CA activity with extremely low IPTG.

\section{Conversion of lysine to DAP by the engineered W3110 strains}

It has been reported that the W3110 strain could tolerant to $20 \mathrm{~g} / \mathrm{L}$ DAP (Qian et al. 2011). Herein, the DAP toxicity test was performed in 4 strains by the ratio of viable cell which defined as the ratio of biomass between DAP addition and without addition. It showed that the cell would dramatically reduce after the DAP of $10 \mathrm{~g} / \mathrm{L}$ was added, but W3110 possess higher survival rate than BL21(DE3), in which the viable cell percent was $32.1 \%$, $34.0 \%, 42.8 \%$ and $36.6 \%$ for BL21(DE3), W3110:IL5, W3110::L5 and W3110::pI (Additional file 1: Fig. S3). Afterwards, two CadA-containing plasmids with or without $l a c \mathrm{I} /$ lacO (i.e., pET28a(+)-CadA and pSU-T7-CadA) were transformed into four strains and the in vivo DAP production was conducted to verify the function of lysine decarboxylase.

The design of pET28a(+)-CadA is shown in Fig. 5a. We used different concentrations of IPTG to test the CadA expression in the four strains (Fig. $5 \mathrm{~b}$ e). More
CadA was expressed with $0.1 \mathrm{mM}$ IPTG than that with $0.01 \mathrm{mM}$ IPTG in BL21(DE3) (Fig. 5b). However, CadA in W3110::IL5 was only overexpressed with $0.1 \mathrm{mM}$ IPTG, and expressed with a critically low amount of protein by $0.01 \mathrm{mM}$ IPTG (Fig. 5c). Furthermore, CadA could be expressed in a critically low IPTG (i.e., $0.001 \mathrm{mM}$ ) in W3110::L5 (Fig. 5d). On the other hand, only W3110::pI expressed the higher CadA with $0.01 \mathrm{mM}$ IPTG (Fig. 5e). To further quantify the relative amount of CadA by densitometry through the software of ImageLab ${ }^{\circledR}$, we found that W3110::pI with $0.01 \mathrm{mM}$ IPTG was 3.03-fold which was even higher than that in the BL21(DE3) with $0.1 \mathrm{mM}$ IPTG (i.e., 2.62-fold), thus the highest expression occurred in W3110::pI (Additional file 1: Table S2). For the in vivo lysine production, lysine, IPTG, and PLP were added at $50 \mathrm{~g} / \mathrm{L}, 0.1 \mathrm{mM}$, and $0.01 \mathrm{mM}$ during the initial exponential phase (i.e., $3 \mathrm{~h}$ ). All the strains possessed the highest DAP production at $24 \mathrm{~h}$ as pET28a(+)-CadA was used (Table 4). The highest lysine consumption in BL21(DE3) (+) and W3110::IL5(+) was only $21.6 \mathrm{~g} / \mathrm{L}$ and $18.13 \mathrm{~g} / \mathrm{L}$, respectively. However, lysine could be more efficiently utilized in the W3110::L5 and W3110::pI with a $45 \mathrm{~g} / \mathrm{L}$ and $32.41 \mathrm{~g} / \mathrm{L}$ consumption of lysine. Therefore, the highest DAP production were obtained from W3110::L5(+) with $45.01 \mathrm{~g} / \mathrm{L}$ lysine consumption, $32.2 \mathrm{~g} / \mathrm{L}$ DAP, $1.34 \mathrm{~g}-\mathrm{DAP} / \mathrm{L} / \mathrm{h}$ productivity and $91.73 \%$ yield at $24 \mathrm{~h}$ (Table 4 ).

The protein expression in pSU-T7-CadA without $l a c \mathrm{I} /$ lac $\mathrm{O}$ (Fig. 5f) was analyzed in four different 


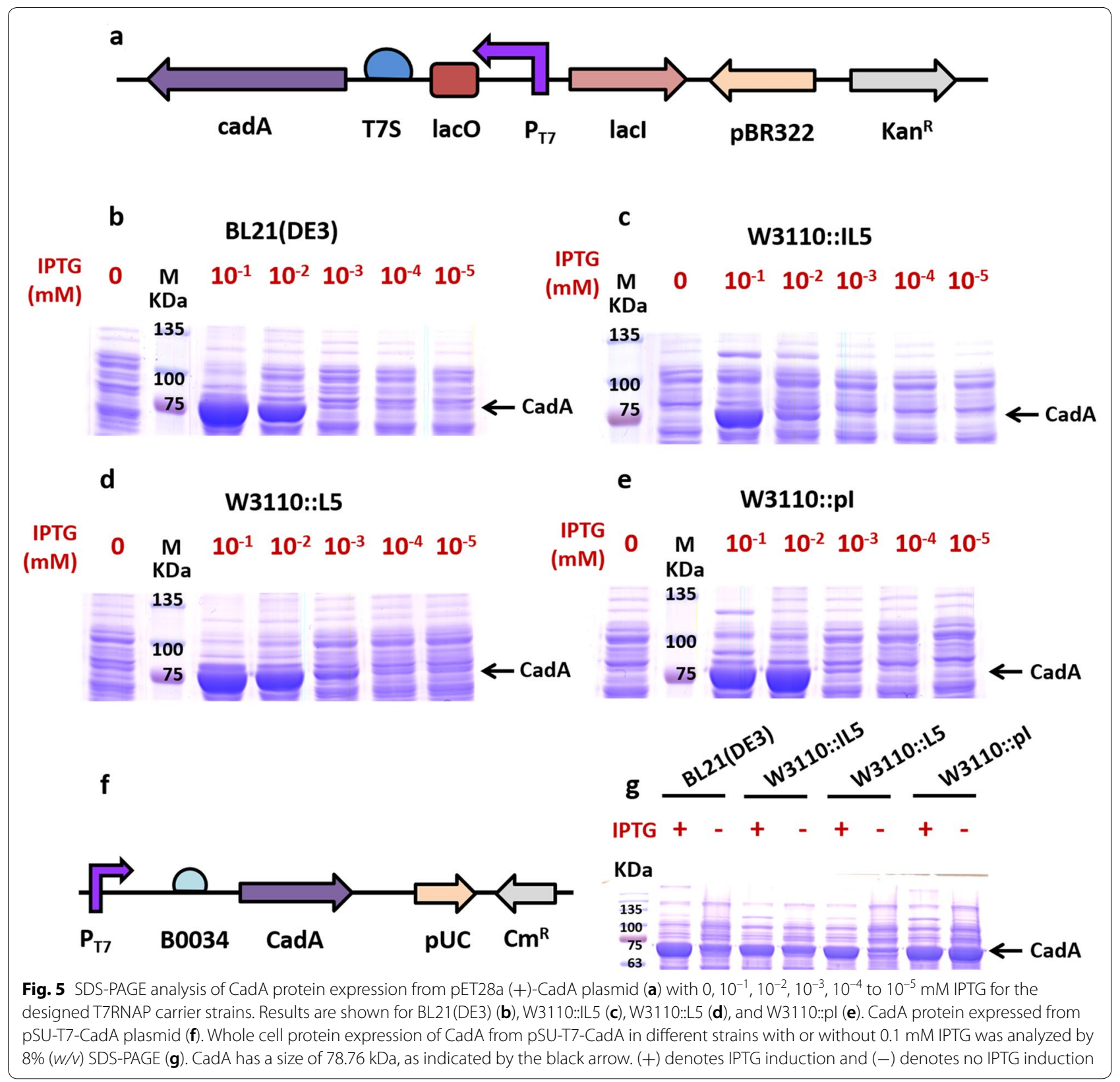

strains. The leakage of CadA was lower in W3110::L5 than in BL21(DE3) and W3110::IL5 (Fig. 5g). The CadA expressions in W3110::pI(-) and $(+)$ are similar, which indicated constitutive $\mathrm{P}_{\text {LacI }}$ promoter was effective. The in vivo DAP production ability for the pSU-T7-CadA-harbored strains is shown in Table 5, the lysine consumption of all strains (except for W3110::IL5) reached $80 \%$ yield at $12 \mathrm{~h}$, while DAP yield decreased until $24 \mathrm{~h}$, mainly due to DAP would be further utilized in the metabolic pathway. The best condition was used W3110::pI(-) to obtain $36.9 \mathrm{~g} / \mathrm{L}$ DAP,
$3.08 \mathrm{~g}-\mathrm{DAP} / \mathrm{L} / \mathrm{h}$ productivity and $103.4 \%$ yield by $\mathrm{pSU}-$ T7-CadA (Table 5). It is reasonable that the yield value was higher than $100 \%$, because according to the retention time (Additional file 1: Fig. S4a) and calibration curve (Additional file 1: Fig. S4b) of HPLC analysis, the lysine concentration in LB medium was approximately $1.61 \mathrm{~g} / \mathrm{L}$. On comparing the results between pSU-T7CadA and pET28a(+)-CadA, a significant enhancement in the lysine consumption rate was observed for pSUT7-CadA. The strains harboring the pSU-T7-CadA consumed up to $41.59,37.35,41.98$ and $42.09 \mathrm{~g} / \mathrm{L}$ lysine 
Table 4 Biomass, lysine consumption, DAP titer, DAP productivity, yield of in vivo time-course with pET28a(+)-CadA plasmid and $50 \mathrm{~g} / \mathrm{L}$ lysine in BL21(DE3), W3110::IL5, W3110::L5 and W3110::pl, respectively

\begin{tabular}{|c|c|c|c|c|c|}
\hline Strain* & Time (h) & $\begin{array}{l}\text { Lysine consumption } \\
\text { (g/L) }\end{array}$ & DAP titer $(\mathrm{g} / \mathrm{L})$ & $\begin{array}{l}\text { Productivity (g } \\
\text { DAP/L/h) }\end{array}$ & Yield (g/g, \%) \\
\hline \multirow[t]{3}{*}{ BL21(DE3) (+) } & 6 & $9.07 \pm 1.5$ & $2.5 \pm 0.1$ & $0.42 \pm 0.07$ & $6.78 \pm 1.17$ \\
\hline & 12 & $9.40 \pm 1.7$ & $5.2 \pm 1.0$ & $0.43 \pm 0.08$ & $13.80 \pm 2.50$ \\
\hline & 24 & $21.60 \pm 1.4$ & $11.3 \pm 1.3$ & $0.47 \pm 0.06$ & $30.05 \pm 3.95$ \\
\hline \multirow[t]{3}{*}{ W3110:IIL5 (+) } & 6 & $9.14 \pm 2.4$ & $4.0 \pm 1.5$ & $0.67 \pm 0.25$ & $11.59 \pm 2.09$ \\
\hline & 12 & $16.67 \pm 3.7$ & $10.4 \pm 1.9$ & $0.87 \pm 0.16$ & $29.38 \pm 1.80$ \\
\hline & 24 & $18.13 \pm 0.3$ & $13.6 \pm 1.6$ & $0.57 \pm 0.07$ & $38.12 \pm 5.89$ \\
\hline \multirow[t]{3}{*}{ W3110::L5 (+) } & 6 & $17.13 \pm 1.8$ & $11.8 \pm 0.1$ & $1.97 \pm 0.02$ & $33.62 \pm 4.45$ \\
\hline & 12 & $40.90 \pm 2.8$ & $29.0 \pm 2.0$ & $2.42 \pm 0.16$ & $82.46 \pm 7.62$ \\
\hline & 24 & $45.01 \pm 1.2$ & $32.2 \pm 0.2$ & $1.34 \pm 0.01$ & $91.73 \pm 8.07$ \\
\hline \multirow[t]{3}{*}{ W3110::pl (+) } & 6 & $14.50 \pm 3.7$ & $10.12 \pm 1.1$ & $1.69 \pm 0.18$ & $29.05 \pm 2.51$ \\
\hline & 12 & $28.45 \pm 3.0$ & $19.85 \pm 2.1$ & $1.65 \pm 0.17$ & $56.96 \pm 3.05$ \\
\hline & 24 & $32.41 \pm 2.0$ & $22.61 \pm 2.4$ & $0.94 \pm 0.10$ & $64.89 \pm 1.01$ \\
\hline
\end{tabular}

${ }^{*}(+)$ means with IPTG induction. The errors represent the standard derivation of 3 independent experiments $(n=3)$

Table 5 Biomass, lysine consumption, DAP titer, DAP productivity, yield of in vivo time-course with pSU-T7-CadA plasmid and $50 \mathrm{~g} / \mathrm{L}$ lysine in BL21(DE3), W3110::IL5, W3110::L5 and W3110::pl, respectively

\begin{tabular}{|c|c|c|c|c|c|}
\hline Strain & Time (h) & $\begin{array}{l}\text { Lysine consumption } \\
\text { (g/L) }\end{array}$ & DAP titer $(\mathrm{g} / \mathrm{L})$ & $\begin{array}{l}\text { Productivity (g-DAP/ } \\
\text { L/h) }\end{array}$ & Yield (g/g, \%) \\
\hline \multirow[t]{3}{*}{ BL21(DE3) (+) } & 6 & $24.21 \pm 1.3$ & $18.3 \pm 1.2$ & $3.05 \pm 0.05$ & $51.3 \pm 1.2$ \\
\hline & 12 & $38.94 \pm 2.2$ & $32.4 \pm 2.5$ & $2.70 \pm 0.02$ & $90.7 \pm 3.2$ \\
\hline & 24 & $41.59 \pm 1.9$ & $28.0 \pm 1.5$ & $1.17 \pm 0.01$ & $78.4 \pm 4.3$ \\
\hline \multirow[t]{3}{*}{ W3110::IL5 (+) } & 6 & $16.56 \pm 0.6$ & $12.8 \pm 0.5$ & $2.13 \pm 0.03$ & $35.9 \pm 2.9$ \\
\hline & 12 & $31.14 \pm 1.1$ & $22.4 \pm 1.1$ & $2.60 \pm 0.04$ & $62.7 \pm 1.6$ \\
\hline & 24 & $37.35 \pm 1.6$ & $23.9 \pm 0.9$ & $1.00 \pm 0.01$ & $66.9 \pm 1.8$ \\
\hline \multirow[t]{3}{*}{ W3110::L5 (+) } & 6 & $19.92 \pm 1.0$ & $15.4 \pm 0.3$ & $2.56 \pm 0.02$ & $43.1 \pm 1.9$ \\
\hline & 12 & $37.50 \pm 2.4$ & $29.3 \pm 0.5$ & $2.44 \pm 0.05$ & $82.1 \pm 1.7$ \\
\hline & 24 & $41.98 \pm 1.4$ & $24.9 \pm 0.8$ & $1.04 \pm 0.01$ & $69.7 \pm 12.5$ \\
\hline \multirow[t]{3}{*}{ W3110::pl (+) } & 6 & $32.51 \pm 1.1$ & $25.4 \pm 1.6$ & $4.24 \pm 0.07$ & $71.1 \pm 3.2$ \\
\hline & 12 & $40.22 \pm 1.7$ & $31.9 \pm 2.0$ & $2.66 \pm 0.05$ & $89.4 \pm 3.5$ \\
\hline & 24 & $42.09 \pm 1.9$ & $26.3 \pm 1.9$ & $1.10 \pm 0.02$ & $73.7 \pm 4.2$ \\
\hline \multirow[t]{3}{*}{ W3110::pl (-) } & 6 & $41.25 \pm 1.1$ & $36.7 \pm 2.0$ & $6.11 \pm 0.11$ & $102.8 \pm 2.7$ \\
\hline & 12 & $43.85 \pm 1.5$ & $36.9 \pm 1.3$ & $3.08 \pm 0.09$ & $103.4 \pm 3.0$ \\
\hline & 24 & $44.69 \pm 0.9$ & $31.4 \pm 2.8$ & $1.31 \pm 0.02$ & $88.0 \pm 2.2$ \\
\hline
\end{tabular}

* (+) means with IPTG induction; (-) means without IPTG induction. The errors represent the standard derivation of 3 independent experiments $(n=3)$

for BL21(DE3) (+), W3110::IL5(+), W3110::L5(+) and W3110::pI(+) at $24 \mathrm{~h}$, while the lysine consumption of strains harboring the pET28(+)-CadA was only 21.6, $18.13,45.01$ and $32.41 \mathrm{~g} / \mathrm{L}$ in the same strains (Tables 4 and 5). Previous studies have reported that the W3110 was a candidate for chemical production (Dong et al. 2017; Huang et al. 2017), thus we further extended the feasibility to apply the T7-based constitutive system in W3110 derivatives (i.e., without the $l a c \mathrm{I} / \mathrm{lac} \mathrm{O}$ regulation) in W3110 for chemical production due to higher chemical production rate and precursor consumption rate.

\section{Discussion}

Tunable protein expression is crucial for synthetic and system biology. One of the powerful tools is the T7RNAP and its orthogonal T7 promoter. The W3110 as an eminent $E$. coli strain has been reported with high capability of different toxic chemicals (Qian et al. 2011; Li et al. 2016). Consequently, W3110 has been equipped with 
the T7RNAP onto the chromosome. For examples, Liu and his colleagues has constructed the W3110(DE3), which entirely encompasses the same genetic design of BL21(DE3), to produce D-xylonic acid (Liu et al. 2012). In this study, we provide three new W3110 strains equipped with different cassette of the T7RNAP as W3110::IL5, W3110::L5 and W3110::pI, which is achieved by the HK022 site-specific recombination, and displayed its feasibility to produce heterologous protein and chemical production. Besides, the IPTG and lacO/lacI effect was further been elucidated.

From our results, W3110 showed a strong lac operon because the lac $\mathrm{Z}$ was overexpressed than that in BL21(DE3) when IPTG was expressed (Table 3), which was the first observation in our best knowledge. LacI partition has already been proven to occur and applied for various applications. Cranenburgh and his coworkers developed a plasmid stabilization system, in which the plasmid containing multiple lac $\mathrm{O}$ sequence in the cell competes with lacI binding and prevents the obligatory to an essential gene (Chamberlin et al. 1970; Cranenburgh et al. 2004). On the other hand, the T7RNAP was immensely overexpressed in W3110 than that in BL21(DE3) from our design, which elucidated the expression of insertion gene will be influenced by the surrounding DNA context that including the promoter, RBS or even a terminator (Rhodius et al. 2012). It has been supposed that the higher T7RNAP of W3110::IL5 than that in W3110::L5 was also contributed by the surrounding DNA context to influence the lacI expression, thus further to affect the T7RNAP expression. Moreover, recently, the chromosome-base gene expression has been elucidated in the aspect of the gene locus (Yang et al. 2019). The gene expression level must be determined by the easiness to relocate the gene to the nucleoid periphery, which further supported our explanation.

When using single or multiple copy of T7 cassette in $E$. coli, it would not affect the protein expression (Chen et al. 2012). Therefore, we selected the plasmid with different types and replication origin (i.e., 15-20 for pET and 40-60 for pSU, respectively), but especially to explore the effect of $l a c \mathrm{I} / l a c \mathrm{O}$ regulator. In a $l a c \mathrm{I} / l a c \mathrm{O}$ containing plasmid, it showed that the protein expression only occurred as IPTG existed, while, as the plasmid without $l a c \mathrm{I} / l a c \mathrm{O}$ was utilized, the expression could be detected in absence or presence of IPTG. As the $l a c \mathrm{I} / l a c \mathrm{O}$ was not encompassed in the plasmid (i.e., pSU), the leakage expression was observed, but the protein expression with induction was still higher than that without induction in BL21(DE3), W3110::IL5 and W3110::L5, which is reasonable because the lacI on the chromosome could still sufficiently repress the $\mathrm{P}_{\mathrm{LacUV}}$ with native lac $\mathrm{RBS}$ to express T7RNAP. On the other hand, in pSU plasmid series, W3110::pI expressed similar amount of heterologous protein with or without IPTG, which was attributed to the highly leakage level of T7RNAP.

In fact, to establish a tightly regulated chromosomebased gene expression is intricate due to the difficulty to well-balance the promoter strength, lacI and $l a c \mathrm{O}$ amount (Schuller et al. 2020). Besides, with the similar promoters of $\mathrm{P}_{\text {LacI }}$ and $\mathrm{P}_{\text {LacUV5 }}$ (Rosano and Ceccarelli 2014), the strength of RBS dominates the leakage expression of T7RNAP, where the B0034 RBS was extremely stronger than the lac native RBS (Additional file 1: Fig. S5).The in vivo DAP production was also affected and displayed higher DAP yield in a short-term (i.e., 6 and $12 \mathrm{~h}$ in Table 5) as the plasmid without $l a c \mathrm{I} / l a c \mathrm{O}$ was used, while the time used for highest production by plasmid with lacI/lac $\mathrm{O}$ must be extended to $24 \mathrm{~h}$ (Table 4).

IPTG dose response is another point that have to be considered in an inducible system as $\mathrm{pET}$ with lacI/lac $\mathrm{O}$ was used (Yi and Ng 2020). In our results, W3110::IL5 must be induced by $0.1 \mathrm{mM}$ to obtain the enough recombinant protein, while W3110::L5 and W3110:pI only used $0.01 \mathrm{mM}$. Even with the high expression of recombinant protein, the solubility would further affect the function of the recombinant protein (Tan et al. 2017), supporting the CA result where the optimal activity was occurred with $0.01 \mathrm{mM}$ IPTG in the three engineered W3110 strains (Fig. 4). Furthermore, the high orthogonality of T7 system was reported as an energy-intensive process (Tan and Ng 2020), leading to less energy in folding the recombinant protein (Baneyx and Mujacic 2004). The in vivo production of DAP by W3110::pI harboring pSU-T7CadA produced higher DAP without induction, primarily due to the cellular energy was more concentrated for lysine and DAP transportation as well as PLP regeneration (Xue et al. 2020).

\section{Conclusion}

In this study, the characterization of three engineered W3110-equipped with T7RNAP was accomplished as well as the difference of the $l a c \mathrm{I} /$ lac $\mathrm{O}$ regulation between W3110 and BL21(DE3) strains was proposed. Among all, the most robust one, W3110::pI strain with a T7RNAP driven by the promoter $\mathrm{P}_{\text {Lacl }}$, enables effective, stable and constitutive production of several recombinant proteins and chemicals while strain W3110::L5 showed the similar capacity to produce the recombinant protein, but higher ability to produce chemical as compared to the commercial BL21(DE3). Even though the W3110::IL5 does not behave efficiently as the other strains, it provides the new insights into the difference of Lac operon between $\mathrm{B}$ and $\mathrm{W}$ derivatives. Therefore, we not only provided a cost-effective, robust and novel engineered W3110 strain 
as a cell factory for recombinant technology, but also presented more understanding of different $E$. coli strains.

\section{Supplementary information}

Supplementary information accompanies this paper at https://doi. org/10.1186/s40643-020-00342-6.

Additional file 1: Table S1. Primers and the sequences used in this study. Table S2. Plasmids used in this study. Fig. S1. The DNA sequencing result of sgRNA (A) sg::speE, (B) sg::puuA, (C) sg::speG, (D) sg::ygjG, (E) sg::speG-ygjG, (F) sg::puuA-speG-ygjG, and (G) sg::speE-puuA-speG-ygjG. The 20 bp sgRNA sequence was indicated in purple rectangle of sg::speE, in blue rectangle of sg::puuA, in green rectangleof sg::speG and in orange rectangle of sg::ygjG. Fig. S2. The cell growth curves of BL21(DE3) and its derivatives which harboring plasmids for single gene repression plasmid or only dCas9 protein (white triangle) during the $24 \mathrm{~h}$.

\section{Acknowledgements}

The authors are grateful for financial support from the Ministry of Science and Technology (MOST 108-2221-E-006-004-MY3, MOST 108-2218-E-006-006, and MOST 108-2621-M-006-015) in Taiwan.

\section{Authors' contributions}

ISN and WWT conceived and designed research. WWT and SIT conducted experiments. ISN, WWT and SIT analyzed data and wrote the manuscript. All authors read and approved the final manuscript.

\section{Funding}

This research is supported by Ministry of Science and Technology (MOST 108-2221-E-006-004-MY3, MOST 108-2218-E-006-006, and MOST 108-2621-M006-015) in Taiwan.

\section{Availability of data and materials}

The authors approved the availability of data and materials for publishing the manuscript.

\section{Ethics approval and consent to participate}

All the authors have read and agreed to the ethics for publishing the manuscript.

\section{Consent for publication}

The authors approved the consent for publishing the manuscript.

\section{Competing interests}

The authors declare that they have no competing interests.

Received: 6 June 2020 Accepted: 3 October 2020

Published online: 16 October 2020

\section{References}

Atsumi S, Cann AF, Connor MR, Shen CR, Smith KM, Brynildsen MP, Liao JC (2008) Metabolic engineering of Escherichia coli for 1-butanol production. Metab Eng 10:305-311

Baneyx F, Mujacic M (2004) Recombinant protein folding and misfolding in Escherichia coli. Nat Biotechnol 22:1399-1408

Chamberlin M, Mcgrath J (1970) Waskell L (1970) New RNA polymerase from Escherichia coli infected with bacteriophage T7. Nature 228:227

Chen PT, Chiang CJ, Wang JY, Lee MZ, Chao YP (2011) Genomic engineering of Escherichia coli for production of intermediate metabolites in the aromatic pathway. J Taiwan Inst Chem Eng 42:34-40

Chen PT, Chiang CJ, Chen YT, Lin HC, Liu CH, Chao YP, Shaw JF (2012) Strategy for stable and high-level expression of recombinant trehalose synthase in Escherichia coli. J Agric Food Chem 60:6063-6068
Chung ME, Yeh IH, Sung LY, Wu MY, Chao YP, Ng IS, Hu YC (2016) Enhanced integration of large DNA into E. coli chromosome by CRISPR/Cas9. Biotechnol Bioeng 114:172-183

Cranenburgh RM, Lewis KS, Hanak JA (2004) Effect of plasmid copy number and lac operator sequence on antibiotic-free plasmid selection by operator-repressor titration in Escherichia coli. J Mol Microbiol Biotechnol 7:197-203

Datta S, Costantino N, Court DL (2006) A set of recombineering plasmids for gram-negative bacteria. Gene 379:109-115

Dong X, Chen X, Qian Y, Wang Y, Wang L, Qiao W, Liu L (2017) Metabolic engineering of Escherichia coli W3110 to produce L-malate. Biotechnol Bioeng 114:656-664

Du FL, Yu HL, Xu JH, Li CX (2014) Enhanced limonene production by optimizing the expression of limonene biosynthesis and MEP pathway genes in E. coli. Bioresour Bioprocess 1:10

Goeddel DV, Kleid DG, Bolivar F, Heyneker HL, Yansura DG, Crea R, Hirose T, Kraszewski A, Itakura K, Riggs AD (1979) Expression in Escherichia coli of chemically synthesized genes for human insulin. Proc Natl Acad Sci USA 76:106-110

Haldimann A, Wanner BL (2001) Conditional-replication, integration, excision, and retrieval plasmid-host systems for gene structure-function studies of bacteria. J Bacteriol 183:6384-6393

Hsu KP, Tan SI, Chiu CY, Chang YK, Ng IS (2019) ARduino-pH Tracker and screening platform for characterization of recombinant carbonic anhydrase in Escherichia coli. Biotechnol Prog 35:e2834

Huang CJ, Lin H, Yang X (2012) Industrial production of recombinant therapeutics in Escherichia coli and its recent advancements. J Ind Microbiol 39:383-399

Huang CY, Ting WW, Chen YC, Wu PY, Dong CD, Huang SF, Lin HY, Li SF, Ng IS, Chang JS (2020) Facilitating the enzymatic conversion of lysine to cadaverine in engineered Escherichia coli with metabolic regulation by genes deletion. Biochem Eng J 156:107514

Huang JF, Liu ZQ, Jin LQ, Tang XL, Shen ZY, Yin HH, Zheng YG (2017) Metabolic engineering of Escherichia coli for microbial production of L-methionine. Biotechnol Bioeng 114:843-851

Jiang W, Bikard D, Cox D, Zhang F, Marraffini LA (2013) RNA-guided editing of bacterial genomes using CRISPR-Cas systems. Nat Biotechnol 31:233

Jo M, Noh MH, Lim HG, Kang CW, Im DK, Oh MK, Jung GY (2019) Precise tuning of the glyoxylate cycle in Escherichia coli for efficient tyrosine production from acetate. Microb Cell Fact 18:57

Kang D, Kim Y, Cha H (2002) Comparison of green fluorescent protein expression in two industrial Escherichia coli strains, BL21 and W3110, under co-expression of bacterial hemoglobin. Appl Microbiol Biotechnol 59:523-528

Kim YH, Kim HJ, Shin JH, Bhatia SK, Seo HM, Kim YG, Lee YK, Yang YH, Park K (2015) Application of diethyl ethoxymethylenemalonate (DEEMM) derivatization for monitoring of lysine decarboxylase activity. J Mol Catal B Enzym 115:151-154

Li CX, Jiang XC, Qiu YJ, Xu JH (2015) Identification of a new thermostable and alkali-tolerant a-carbonic anhydrase from Lactobacillus delbrueckii as a biocatalyst for $\mathrm{CO}_{2}$ biomineralization. Bioresour Bioprocess 2:44

Li H, Wang B, Zhu L, Cheng S, Li Y, Zhang L, Ding ZY, Gu ZH, Shi GY (2016) Metabolic engineering of Escherichia coli W3110 for L-homoserine production. Process Biochem 51:1973-1983

Li Y, Cirino PC (2014) Recent advances in engineering proteins for biocatalysis. Biotechnol Bioeng 111:1273-1287

Liu H, Valdehuesa KNG, Nisola GM, Ramos KRM, Chung WJ (2012) High yield production of D-xylonic acid from D-xylose using engineered Escherichia coli. Bioresour Technol 115:244-248

Ng IS, Chen T, Lin R, Zhang X, Ni C, Shun D (2014) Decolorization of textile azo dye and Congo red by an isolated strain of the dissimilatory manganese-reducing bacterium Shewanella xiamenensis BC01. Appl Microbiol Biotechnol 98:2297-2308

Ng IS, Hung YH, Kao PH, Zhou Y, Zhang X (2016) CRISPR/Cas9 nuclease cleavage enables marker-free genome editing in Escherichia coli: A sequential study. J Taiwan Inst Chem Eng 68:31-39

Qian ZG, Xia XX, Lee SY (2011) Metabolic engineering of Escherichia coli for the production of cadaverine: a five carbon diamine. Biotechnol Bioeng 108:93-103 
Rhodius VA, Mutalik VK, Gross CA (2012) Predicting the strength of UPelements and full-length E. coli $\sigma$ E promoters. Nucleic Acids Res 40:2907-2924

Rosano GL, Ceccarelli EA (2014) Recombinant protein expression in Escherichia coli: advances and challenges. Front Microbiol 5:172

Schuller A, Cserjan-Puschmann M, Tauer C, Jarmer J, Wagenknecht M, Reinisch D, Grabherr R, Striedner G (2020) Escherichia coli o 70 promoters allow expression rate control at the cellular level in genome-integrated expression systems. Microb Cell Fact 19:1-11

Studier FW, Moffatt BA (1986) Use of bacteriophage T7 RNA polymerase to direct selective high-level expression of cloned genes. J Mol Biol 189:113-130

Tan SI, Ng IS (2020) New Insight into plasmid-driven T7 RNA polymerase in Escherichia coli and use as a genetic amplifier for a biosensor. ACS Synth Biol 9:613-622

Tan SI, Ng IS, Yu YJ (2017) Heterologous expression of an acidophilic multicopper oxidase in Escherichia coli and its applications in biorecovery of gold. Bioresour Bioprocess 4:1-10

Wang X, Wang Y, Liu J, Li Q, Zhang Z, Zheng P, Lu F, Sun J (2017) Biological conversion of methanol by evolved Escherichia coli carrying a linear methanol assimilation pathway. Bioresour Bioprocess 4:41

Wu H, Fan Z, Jiang X, Chen J, Chen GQ (2015) Enhanced production of polyhydroxybutyrate by multiple dividing E. coli. Microb Cell Fact 15:128-140
Xue C, Hsu KM, Ting WW, Huang SF, Lin HY, Li SF, Chang JS, Ng IS (2020) Efficient biotransformation of L-lysine into cadaverine by strengthening pyridoxal 5'-phosphate-dependent proteins in Escherichia coli with cold shock treatment. Biochem Eng J 161:107659

Yang S, Kim S, Kim DK, An HJ, Son JB, Gynna AH, Lee NK (2019) Transcription and translation contribute to gene locus relocation to the nucleoid periphery in E. coli. Nat Commun 10:1-12

Yi YC, Ng IS (2020) Establishment of toolkit and T7RNA polymerase/promoter system in Shewanella oneidensis MR-1. J Taiwan Inst Chem Eng 109:8-14

Yoon SH, Han MJ, Jeong H, Lee CH, Xia XX, Lee DH, Shim JH, Lee SY, Kim JF (2012) Comparative multi-omics systems analysis of Escherichia coli strains B and K-12. Genome Biol 13:R37

Yu D, Ellis HM, Lee EC, Jenkins NA, Copeland NG (2000) An efficient recombination system for chromosome engineering in Escherichia coli. Proc Nat Acad Sci USA 97:5978-5983

\section{Publisher's Note}

Springer Nature remains neutral with regard to jurisdictional claims in published maps and institutional affiliations.

\section{Submit your manuscript to a SpringerOpen ${ }^{\odot}$ journal and benefit from:}

- Convenient online submission

- Rigorous peer review

- Open access: articles freely available online

- High visibility within the field

- Retaining the copyright to your article

Submit your next manuscript at $\boldsymbol{\nabla}$ springeropen.com 